Open Access

\title{
Body mass index is associated with higher Gleason score and biochemical recurrence risk following radical prostatectomy in Chinese men: a retrospective cohort study and meta-analysis
}

Pei-De Bai ${ }^{*}$, Meng-Bo Hu${ }^{\dagger}$, Hua Xu, Wen-Hui Zhu, Ji-Meng Hu, Tian Yang, Hao-Wen Jiang ${ }^{*}$ and Qiang Ding

\begin{abstract}
Background: The aim of the study is to investigate whether body mass index (BMI) affected pathological characteristics and biochemical recurrence (BCR) of prostate cancer after radical prostatectomy in Chinese men.

Methods: Medical records of 211 Chinese patients who underwent radical prostatectomy between 2006 and 2014 were retrospectively reviewed, with follow-up time of $24.5 \pm 27.0$ months. Multivariate logistic and Cox regression analyses were applied to address the impact of BMI on adverse pathological outcomes and BCR following prostatectomy. A meta-analysis of published studies from MEDLINE or EMBASE was conducted to determine the relationship between $\mathrm{BMI}$ and BCR following prostatectomy among Asian populations.

Results: Higher BMI was positively correlated with higher biopsy Gleason score (odds ratios (OR) 1.163, $95 \%$ confidence interval $(C l) 1.023-1.322, P=0.021)$ and pathological Gleason score (OR 1.220, $95 \%$ Cl 1.056-1.410, $P=0.007)$ in multivariate analysis. BCR was detected in 48 patients $(22.7 \%)$. Multivariate Cox proportional hazards analysis revealed that higher BMI (hazard ratio (HR) 1.145, $95 \% \mathrm{Cl} 1.029-1.273, P=0.013$ ) and prostate-specific antigen (HR 1.659, $95 \% \mathrm{Cl} 1.102-2.497, P=0.015)$ levels were independent predictors of $B C R$. The meta-analysis enrolled eight Asian studies of 4145 patients treated by radical prostatectomy. Based on random-effects approach, a $5 \mathrm{~kg} / \mathrm{m}^{2}$ increase in BMI was correlated with $28 \%$ higher risk of BCR (HR 1.22, $95 \% \mathrm{Cl}$ 0.86-1.72) without statistical significance.
\end{abstract}

Conclusions: The present study suggested that higher BMI was an independent risk factor for a higher Gleason score, as well as an independent predictor of BCR after radical prostatectomy in Chinese patients. Meta-analysis of Asian studies also indicated that obese patients, although without statistical significance, might be more likely to suffer from BCR.

Keywords: Prostatic neoplasms, Body mass index, Prostatectomy, Biochemical recurrence, Gleason score

\footnotetext{
* Correspondence: 07301010196@fudan.edu.cn; haowenj@yahoo.com

${ }^{\dagger}$ Equal contributors

Department of Urology, Huashan Hospital, Fudan University, No.12 Middle

Wulumuqi Road, Shanghai 200040, China
}

( Biomed Central (c) 2015 Bai et al. Open Access This article is distributed under the terms of the Creative Commons Attribution 4.0 International License (http://creativecommons.org/licenses/by/4.0/), which permits unrestricted use, distribution, and reproduction in any medium, provided you give appropriate credit to the original author(s) and the source, provide a link to the Creative Commons license, and indicate if changes were made. The Creative Commons Public Domain Dedication waiver (http://creativecommons.org/publicdomain/zero/1.0/) applies to the data made available in this article, unless otherwise stated. 


\section{Background}

Obesity, as a growing public health concern around the world, was linked to the development and progression of various cancers [1]. However, the association between prostate cancer and obesity, generally measured by body mass index (BMI), remained controversial [2]. Some previous studies revealed a significant association between obesity and a higher incidence of prostate cancer $(\mathrm{PCa})$ [3], worse pathologic outcome [4], and higher incidence of cancer-specific mortality [5]. However, other researches failed to find such an obvious association between obesity and PCa [6, 7].

Attributed to the westernization of lifestyle and daily diet, the prevalence of obesity as well as prostate cancer was increasing rapidly in Asia (especially in China, Japan, and Korea) in the past few decades. However, the researches into the relationship between BMI and different clinicopathological characteristics and treatment outcomes in $\mathrm{PCa}$ patients after radical prostatectomy (RP) remained rare and inconsistent in Asia [8-10].

Therefore, we conducted a retrospective cohort study to evaluate the impact of BMI on different clinicopathological features and biochemical recurrences (BCR) after RP in Chinese PCa patients. Meanwhile, we carried out a systematic review and meta-analysis of previous studies discussing the relationship between obesity and BCR in Asia. The significance of this analysis could be farreaching, as proper strategies towards patients with different BMI might help improve the prognosis of $\mathrm{PCa}$ and cost-effectiveness of postoperative treatment.

\section{Methods}

\section{Study population}

A total of 213 consecutive patients with clinically localized PCa underwent RP from February 2006 to December 2014 at our institute. The study was approved by the institutional review board, and written informed consent forms were signed by all patients prior to their inclusion of the study. No patient had a history of prostate surgery, hormonal therapy, chemotherapy, or radiation therapy. All patients in the study were operated on by two urologists with more than 10 years' experience in prostatectomy. Two patients were excluded from further analysis because of missing BMI data. RP was achieved using either open (18 patients) or laparoscopic (193 patients) approach.

\section{Clinicopathological characteristics}

Data assessed included patient age at surgery, BMI, preoperative prostate-specific antigen (PSA) level, digital rectal examination (DRE) outcomes, biopsy Gleason score, clinical stage, prostate volume (PV), prostate nodule assessed via preoperative transrectal ultrasound (TRUS), pathological Gleason score, surgical margin status, local invasion status, lymph node involvement, and postoperative follow-up PSA data. BMI $\left(\mathrm{kg} / \mathrm{m}^{2}\right)$ was calculated as weight ( $\mathrm{kg})$ divided by the square of height $(\mathrm{m})$, and all patients' height and weight information were recorded preoperatively. The patients were categorized into three groups: normal weight group (BMI $<23 \mathrm{~kg} / \mathrm{m}^{2}$ ), overweight group (BMI 23-24.9 $\mathrm{kg} / \mathrm{m}^{2}$ ), and obese group (BMI $\geq 25 \mathrm{~kg} / \mathrm{m}^{2}$ ) on the basis of Asia-Pacific criteria of obesity. Pathological evaluation of biopsy and surgical specimens was performed according to the Gleason grading system and the 2002 TNM classification. All of the biopsy and pathological specimens were obtained and evaluated in the same histopathology lab in our institute. All of the pathological results were confirmed by senior pathologists who specialized in urological pathology.

The association of different BMI categories with clinicopathological characteristics and BCR was examined. After surgery, PSA measurements were performed every 3 months for the first year and thereafter every 3 to 6 months. The date of biochemical recurrence was defined as when the serum PSA level exceeded $0.2 \mathrm{ng} / \mathrm{ml}$, or salvage therapy was initiated even if PSA did not exceed $0.2 \mathrm{ng} / \mathrm{ml}$.

\section{Statistical analysis}

We assessed differences in clinicopathological characteristics across BMI categories, using the Kruskal-Wallis test for continuous variables and the chi-squared test for categorical variables. PSA and PV were analyzed after logarithmic transformations because these variables were not normally distributed. Odds ratios (OR) and $95 \%$ confidence intervals (CI) for adverse pathological outcomes were estimated for categorical BMI using logistic regression analysis with or without adjusting for patient age, PSA, PV, clinical stage, and biopsy Gleason score. BCR-free survival was determined using Kaplan-Meier plots and log-rank test. Univariate and multivariate Cox proportional hazards regression models were adopted to find out the independent risk factor that predicted BCR. Statistical analyses were performed using the SPSS version 21 (SPSS, Chicago, IL, USA). Statistical significance was defined as a two-tailed $P<0.05$.

\section{Systematic review and meta-analysis}

We searched the MEDLINE and EMBASE databases on April 1, 2015, for English-written studies discussing the relationship between BCR and obesity in Asian populations. The search queries were as follows: ("obesity" or "body mass index" or "BMI") and (prostate cancer) and (radical prostatectomy) and ("recurrence" or "progression" or "failure").

Two investigators (Bai and $\mathrm{Hu}$ ) assessed the eligibility of each study independently. Only clinical studies that were conducted in Asia with direct comparison between $\mathrm{BMI}$ and $\mathrm{BCR}$ following $\mathrm{RP}$ were incorporated in the 
review. We excluded reviews, editorials, meta-analysis, non-human studies, non-English-written papers, and studies for other disease settings. Data extracted from each study were as follows: title, authors, journal, publication year, study period, study population, treatment method, duration of follow-up, BMI categories, hazard ratio (HR) estimates with corresponding $95 \% \mathrm{CI}$, and adjusted confounders in multivariate analysis. HR estimates across different categorical or continuous BMI were converted to the unified estimate for a $5 \mathrm{~kg} / \mathrm{m}^{2}$ increase in BMI using the method stated in our previous study [11]. Unless otherwise stated, we used the most adjusted HR from each study. We assessed the heterogeneity among studies using $Q$ and $I^{2}$ statistics. Publication bias was examined by both Begg's and Egger's tests.

\section{Results}

BMI and clinical characteristics

The clinicopathological characteristics of patients were shown in Table 1. In total, 211 patients diagnosed with PCa with a median age of 68 years were enrolled in this study. The median BMI was $23.9 \mathrm{~kg} / \mathrm{m}^{2}$. In total, $35.5 \%$ of patients were of normal weight (BMI $<23 \mathrm{~kg} / \mathrm{m}^{2}$ ), $33.6 \%$ of patients were overweight (BMI $23-24.9 \mathrm{~kg} / \mathrm{m}^{2}$ ), and $30.8 \%$ were obese (BMI $>25 \mathrm{~kg} / \mathrm{m}^{2}$ ) according to Asia-Pacific criteria. The median preoperative PSA level was $13.4 \mathrm{ng} / \mathrm{ml}$, and the median PV was $36.0 \mathrm{ml}$. When subjects were categorized according to BMI, patients in the overweight group had more TRUS nodules compared with other two groups (chi-squared $P=0.049$ ). No significant differences were observed in age, PSA, PV, and positive DRE findings.

Table 1 Clinicopathological characteristics of patients across different BMI categories

\begin{tabular}{|c|c|c|c|c|c|}
\hline Variables & Total subject & $\mathrm{BMl}<23 \mathrm{~kg} / \mathrm{m}^{2}$ & BMI $23-24.9 \mathrm{~kg} / \mathrm{m}^{2}$ & $\mathrm{BMI} \geq 25 \mathrm{~kg} / \mathrm{m}^{2}$ & $P$ value \\
\hline No. of patients (\%) & 211 & $75(35.5)$ & $71(33.6)$ & $65(30.8)$ & \\
\hline BMI $\left(\mathrm{kg} / \mathrm{m}^{2}\right)$ & & & & & $<0.001$ \\
\hline Median (IQR) & $23.9(3.4)$ & $21.4(2.2)$ & $24.2(1.1)$ & 26.4(1.9) & \\
\hline Range & $16.1-30.1$ & $16.1-22.9$ & $23.0-24.9$ & $25.0-30.1$ & \\
\hline Age (years) & & & & & 0.373 \\
\hline Median (IQR) & 68(8) & $67(11)$ & $70(9)$ & $67(8)$ & \\
\hline Range & $47-86$ & $48-86$ & $56-83$ & $47-81$ & \\
\hline Preoperative PSA (ng/ml) & & & & & 0.607 \\
\hline Median (IQR) & 13.4(11.9) & $13.5(15.0)$ & $14(10.3)$ & $11.5(13.1)$ & \\
\hline Range & $1.4-293.3$ & $1.7-293.3$ & $1.4-62.5$ & $2.3-85.6$ & \\
\hline Prostate volume (ml) & & & & & 0.326 \\
\hline Median (IQR) & $36(16)$ & $37(13)$ & $36(17)$ & $35.5(18)$ & \\
\hline Range & $12-98$ & $13-89$ & $19-98$ & $12-91$ & \\
\hline Positive DRE finding (\%) & $68(67.6)$ & $23(31.1)$ & $24(33.8)$ & $21(32.3)$ & 0.94 \\
\hline TRUS nodule (\%) & $106(50.7)$ & $31(41.9)$ & $44(62.0)$ & $31(48.4)$ & 0.049 \\
\hline Clinical stage ${ }^{\mathrm{b}}(\%)$ & & & & & 0.156 \\
\hline cT1 & $100(47.8)$ & $41(55.4)$ & $28(39.4)$ & $31(48.4)$ & \\
\hline$\geq \mathrm{cT} 2$ & $109(52.2)$ & $33(44.6)$ & $43(60.6)$ & $33(51.6)$ & \\
\hline Biopsy GS (\%) & & & & & 0.222 \\
\hline$\leq 6$ & $82(38.9)$ & $35(46.7)$ & $25(35.3)$ & $22(33.8)$ & \\
\hline$\geq 7$ & $129(61.1)$ & $40(53.3)$ & $46(64.8)$ & $43(66.2)$ & \\
\hline Pathological GS (\%) & & & & & 0.303 \\
\hline$\leq 6$ & $65(30.8)$ & $28(37.3)$ & $20(28.2)$ & $17(26.2)$ & \\
\hline$\geq 7$ & $146(69.2)$ & $47(62.7)$ & $51(71.8)$ & 48(73.8) & \\
\hline Positive surgical margin (\%) & $26(12.3)$ & $9(12.0)$ & $4(5.6)$ & 13(20.0) & 0.039 \\
\hline Extra capsular invasion (\%) & $31(14.7)$ & $13(17.3)$ & $8(11.3)$ & $10(15.4)$ & 0.575 \\
\hline Seminal vesicle invasion (\%) & 24(11.4) & $13(17.3)$ & $4(5.6)$ & $7(10.8)$ & 0.083 \\
\hline Lymph node invasion (\%) & $5(2.4)$ & $2(2.7)$ & $1(1.4)$ & $2(3.1)$ & 0.797 \\
\hline
\end{tabular}

$B M I$ body mass index, IQR interquartile range, PSA prostate-specific antigen, DRE digital rectal examination, TRUS transrectal ultrasound, GS Gleason score ${ }^{a}$ All $P$ values were calculated using Kruskal-Wallis test for continuous variables and chi-squared test for categorical variables

${ }^{\mathrm{b}}$ The clinical stage of two patients was missing according to medical records 


\section{BMI and pathological characteristics}

Various preoperative and postoperative pathological features including biopsy Gleason score, pathological Gleason score, positive surgical margin, extra capsular invasion, seminal vesicle invasion, and lymph node involvement were assessed across BMI categories. Obese patients were at higher risk of having positive surgical margin (chi-squared $P=0.039$ ). The rest of the pathological characteristics did not differ significantly across BMI categories (Table 1). In the multivariate regression model, higher BMI was an independent risk factor for a higher biopsy Gleason score (OR 1.163, 95 \% CI 1.0231.322, $P=0.021$ ) and pathological Gleason score (OR 1.220, 95 \% CI 1.056-1.410, $P=0.007$ ) (Table 2).

\section{$\mathrm{BMI}$ and biochemical recurrence}

Of the 211 patients, 48 (22.7 \%) experienced BCR during a follow-up period of $24.5 \pm 27.0$ months. BCR was observed in 13 of $75(17.3 \%)$ patients in the normal weight group, 15 of $71(21.1 \%)$ patients in the overweight group, and 20 of 64 (30.8 \%) patients in the obese group. The Kaplan-Meier plot indicated a weak statistically significant difference in the incidence of BCR between three groups ( $\log$-rank $P=0.086$, Fig. 1). In univariate Cox proportional hazards analysis (Table 3), higher PSA (HR 1.509, $95 \%$ CI 1.040-2.190, $P=0.03$ ) and categorical BMI $\left(\geq 25 \mathrm{~kg} / \mathrm{m}^{2}\right.$ vs. $<23 \mathrm{~kg} / \mathrm{m}^{2}$, HR $2.087,95 \%$ CI
1.033-4.215, $P=0.04$ ) were both correlated with the $\mathrm{BCR}$ of prostate cancer. In multivariate Cox proportional hazards analysis (Table 3), higher PSA was still associated with an increasing $\mathrm{HR}$ trend with BCR no matter whether included BMI was a continuous or categorical variable $(P=0.015$ and 0.011$)$. Continuous BMI was positively associated with an increased BCR trend (HR 1.145, 95 \% CI 1.029-1.273, $P=0.013)$. Categorical BMI was positively associated with an increasing $\mathrm{HR}$ of BCR $\left(\geq 25 \mathrm{~kg} / \mathrm{m}^{2}\right.$ vs. $<23 \mathrm{~kg} / \mathrm{m}^{2}$, HR $2.937,95 \%$ CI $1.383-$ 6.237, $P=0.005)$.

\section{Systematic review and meta-analysis}

Our literature search yielded 178 potentially relevant studies on the relationship between BMI and BCR of PCa after RP. After screening and full-text assessment, seven studies conducted in Asia met all eligibility criteria $[8-10,12-15]$ and were selected for meta-analysis along with the current study. As shown in Table 4, all eight studies followed a total of 4145 Asian PCa patients after RP from 17 to 58.2 months. Studies were conducted in Japan $(n=5)$, Korea $(n=2)$, and China $(n=1)$. The forest plot of meta-analysis showed that a $5 \mathrm{~kg} / \mathrm{m}^{2}$ increase in BMI was associated with $22 \%$ higher risk of BCR (HR 1.22, $95 \%$ CI $0.86-1.72$, Fig. 2) but failed to present statistical significance. Statistical heterogeneity was observed among the studies $\left(I^{2}=72.9 \%\right)$.

Table 2 Logistic regression analyses of BMl categories with adverse pathological outcomes

\begin{tabular}{|c|c|c|c|c|c|c|c|c|c|}
\hline \multirow[t]{2}{*}{ Pathological outcomes } & \multicolumn{3}{|c|}{ BMI (continuous) } & \multicolumn{3}{|c|}{ BMI $23-24.9 \mathrm{~kg} / \mathrm{m}^{2}$ vs. $<23 \mathrm{~kg} / \mathrm{m}^{2}$} & \multicolumn{3}{|c|}{$\mathrm{BMI} \geq 25 \mathrm{~kg} / \mathrm{m}^{2}$ vs. $<23 \mathrm{~kg} / \mathrm{m}^{2}$} \\
\hline & OR & $95 \% \mathrm{Cl}$ & $P$ value & OR & $95 \% \mathrm{Cl}$ & $P$ value & OR & $95 \% \mathrm{Cl}$ & $P$ value \\
\hline \multicolumn{10}{|l|}{ Biopsy GS ( $\geq 7)$} \\
\hline Crude & 1.079 & $0.973-1.196$ & 0.149 & 1.610 & $0.828-3.132$ & 0.161 & 1.710 & $0.862-3.394$ & 0.125 \\
\hline Multi-adjusted analysis $^{\mathrm{a}}$ & 1.163 & $1.023-1.322$ & 0.021 & 1.940 & $0.873-4.307$ & 0.104 & 2.434 & $1.103-5.371$ & 0.028 \\
\hline \multicolumn{10}{|l|}{ Pathological GS ( $\geq 7$ ) } \\
\hline Crude & 1.090 & $0.978-1.215$ & 0.121 & 1.519 & $0.756-3.051$ & 0.24 & 1.682 & $0.815-3.471$ & 0.159 \\
\hline Multi-adjusted analysis $^{\mathrm{a}}$ & 1.220 & $1.056-1.410$ & 0.007 & 1.983 & $0.828-4.748$ & 0.124 & 3.379 & $1.374-8.309$ & 0.008 \\
\hline \multicolumn{10}{|l|}{ Positive surgical margin } \\
\hline Crude & 1.157 & $0.987-1.357$ & 0.072 & 0.438 & $0.128-1.492$ & 0.187 & 1.833 & $0.727-4.620$ & 0.199 \\
\hline Multi-adjusted analysis $^{\mathrm{a}}$ & 1.169 & $0.959-1.426$ & 0.121 & 0.600 & $0.149-2.406$ & 0.471 & 1.742 & $0.550-5.521$ & 0.345 \\
\hline \multicolumn{10}{|l|}{ Extra capsular invasion } \\
\hline Crude & 1.014 & $0.881-1.167$ & 0.848 & 0.606 & $0.235-1.563$ & 0.3 & 0.867 & $0.352-2.135$ & 0.756 \\
\hline Multi-adjusted analysis $^{a}$ & 1.145 & $0.950-1.381$ & 0.156 & 0.945 & $0.273-3.267$ & 0.929 & 1.687 & $0.551-5.161$ & 0.360 \\
\hline \multicolumn{10}{|l|}{ Seminal vesicle invasion } \\
\hline Crude & 1.006 & $0.860-1.177$ & 0.937 & 0.285 & $0.088-0.920$ & 0.036 & 0.576 & $0.215-1.543$ & 0.272 \\
\hline Multi-adjusted analysis ${ }^{\mathrm{a}}$ & 1.070 & $0.865-1.323$ & 0.532 & 0.414 & $0.104-1.641$ & 0.209 & 0.840 & $0.251-2.810$ & 0.778 \\
\hline \multicolumn{10}{|l|}{ Lymph node involvement } \\
\hline Crude & 1.004 & $0.724-1.391$ & 0.983 & 0.521 & $0.046-5.880$ & 0.598 & 1.159 & $0.159-8.466$ & 0.885 \\
\hline Multi-adjusted analysis ${ }^{\mathrm{a}}$ & 0.946 & $0.666-1.344$ & 0.759 & 0.593 & $0.038-9.142$ & 0.708 & 0.922 & $0.096-8.818$ & 0.944 \\
\hline
\end{tabular}

$O R$ odds ratio, $\mathrm{Cl}$ confidence interval, other abbreviations as in Table 1

${ }^{a}$ Adjusted for age, prostate-specific antigen, prostate volume, digital rectal examination outcomes, transrectal ultrasound outcomes, and clinical stage 


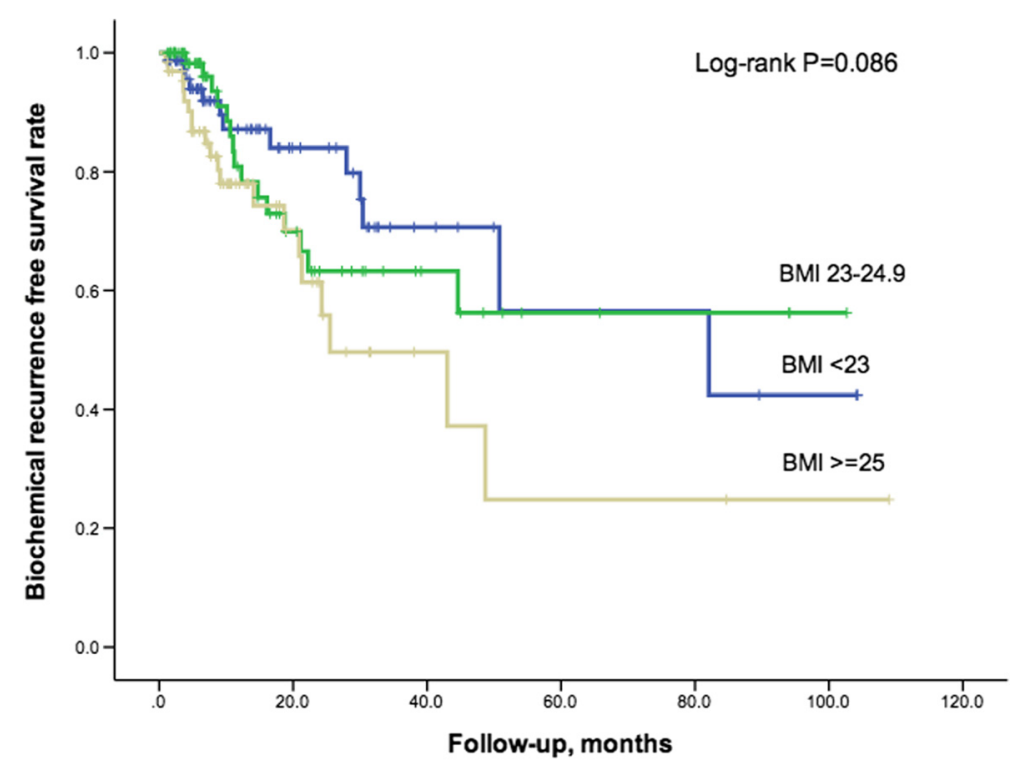

Fig. 1 Kaplan-Meier plot for biochemical recurrence-free survival across BMI categories

Begg's $(P=0.536)$ and Egger's $(P=0.215)$ tests did not indicate publication bias.

\section{Discussion}

The association between BMI and PCa is a global health concern. Unlike the US where most studies showed a positive association between greater BMI and increased aggressiveness of $\mathrm{PCa}$ and risk of $\mathrm{BCR}$ after prostatectomy [16], insufficient and contradictory data had been reported on Asian men. Two studies found that higher BMI independently contributed to biochemical failure of PCa $[8,12]$, while several other studies failed to confirm positive associations between BMI and adverse pathological outcomes or increased BCR [9, 10, 13-15].

As per our knowledge, the present study was the first to report results in a Chinese population, which indicated that higher BMI was an independent risk factor for a higher Gleason score, as well as an independent predictor of BCR after RP. Besides, the present study conducted a systematic review and meta-analysis of the association between BMI and BCR after RP in Asian populations. With a total of 4145 Asian PCa patients from eight studies, a positive association without statistical significance was detected between BMI and BCR.

Till now, the exact mechanisms underlying the positive association between obesity and aggressiveness of PCa were unclear. One possible mechanism for the poor prognosis of $\mathrm{PCa}$ among obese populations was the poor pathological outcomes of an existing tumor. Previous studies reported that obesity had a negative impact on the pathological Gleason score, positive surgical margin, extra capsular invasion, and lymph node involvement [17]. It was generally considered that BMI was positively related to an increased risk of positive surgical margins, for excessive pelvic fat might affect the surgeon's vision and his ability to remove the entire prostate. The results of our study were partly in line with the previous researches.

Other possible mechanisms included were that higher BMI provided a favorable biological microenvironment for survival and progression of the tumor even after RP. Men with higher BMI produced a microenvironment with less testosterone and more estrogen, where $\mathrm{PCa}$ would be less androgen-dependent and more aggressive [18]. Besides, excessive adiposity inside the body may have contributed to the growth of tumor by secreting certain adipokines and inflammatory cytokines [19, 20]. Higher body weight was also associated with increased gene expression of diverse inflammatory transcripts in the nuclear factor kappa B pathway, promoting tumor aggressiveness [21]. Additionally, changes in the metabolic microenvironments of obese men resulted in compensatory hyperinsulinemia as well as increased levels of insulin-like growth factor 1, both of which were proved to encourage carcinogenesis and inhibit apoptosis [22]. In the present study, higher BMI was still associated with BCR even after adjusting for pathological Gleason score and positive surgical margin, which tended to support the microenvironment hypothesis.

Unlike the USA or some European countries [11], the combined HR in the present meta-analysis of Asian studies failed to adopt a positive association with statistical significance between BMI and BCR. The discrepancy between observed findings in Western and Asian populations might be explained by racial differences and differences in cancer screening and management strategy. 
Table 3 Univariate and multivariate Cox proportional hazards analyses for biochemical recurrence-free survival

\begin{tabular}{|c|c|c|}
\hline Variables & $\mathrm{HR}(95 \% \mathrm{Cl})$ & $P$ value \\
\hline \multicolumn{3}{|l|}{ Univariate } \\
\hline Age & 0.976(0.935-1.019) & 0.269 \\
\hline BMI (continuous) & 1.107(0.999-1.227) & 0.053 \\
\hline \multicolumn{3}{|l|}{ BMI (categorical, kg/m²) } \\
\hline$<23$ & Reference & - \\
\hline $23-24.9$ & $1.237(0.588-2.603)$ & 0.575 \\
\hline$\geq 25$ & $2.087(1.033-4.215)$ & 0.040 \\
\hline Preoperative PSA ${ }^{a}$ & $1.509(1.040-2.190)$ & 0.030 \\
\hline$P V^{a}$ & $1.421(0.697-2.894)$ & 0.333 \\
\hline DRE & $1.518(0.860-2.679)$ & 0.15 \\
\hline TRUS & $0.946(0.505-0.1 .770)$ & 0.862 \\
\hline Clinical stage & 1.308(0.653-2.619) & 0.448 \\
\hline Pathological GS ( $\geq 7$ ) & $1.133(0.597-2.152)$ & 0.702 \\
\hline Positive surgical margin & $0.810(0.290-2.263)$ & 0.688 \\
\hline Extra capsular invasion & $1.067(0.453-2.514)$ & 0.883 \\
\hline Seminal vesicle invasion & 1.994(0.779-5.105) & 0.150 \\
\hline Lymph node invasion & 2.835(0.872-9.218) & 0.083 \\
\hline \multicolumn{3}{|l|}{ Multivariate model I } \\
\hline BMI (continuous) & $1.145(1.029-1.273)$ & 0.013 \\
\hline Age & $0.972(0.929-1.017)$ & 0.225 \\
\hline$P S A^{a}$ & $1.659(1.102-2.497)$ & 0.015 \\
\hline Pathological GS ( $\geq 7)$ & $0.991(0.512-1.917)$ & 0.978 \\
\hline Positive surgical margin & $0.442(0.148-1.316)$ & 0.142 \\
\hline \multicolumn{3}{|l|}{ Multivariate model II } \\
\hline \multicolumn{3}{|l|}{ BMI (categorical, kg/m²) } \\
\hline$<23$ & Reference & - \\
\hline $23-24.9$ & $1.583(0.720-3.482)$ & 0.253 \\
\hline$\geq 25$ & $2.937(1.383-6.237)$ & 0.005 \\
\hline Age & $0.971(0.926-1.018)$ & 0.217 \\
\hline$P S A^{a}$ & $1.725(1.132-2.628)$ & 0.011 \\
\hline Pathological GS ( $\geq 7)$ & $1.009(0.525-1.938)$ & 0.979 \\
\hline Positive surgical margin & $0.428(0.144-1.270)$ & 0.126 \\
\hline
\end{tabular}

$H R$ hazard ratio, other abbreviations as in Tables 1 and 2

${ }^{a}$ Variables after logarithmic transformation

The average BMI in the Asian population was far lower than Western counterparts. It was suggested that only when BMI reached a certain threshold (around $30 \mathrm{~kg} / \mathrm{m}^{2}$ ), the correlation would be significant with the increased aggressiveness of prostate cancer [13]. Most Asian obese patients failed to reach such threshold, and there might be insufficient biological changes in these men to promote aggressiveness of PCa. Besides, Asian men possessed higher body fat percentages at the same BMI compared with Western men [23]. Therefore, an Asian patient might have quite different internal biological and endocrine environment from a Western patient at a given BMI. Moreover, quite different from Western diets, Asian diets contained higher levels of phytoestrogens, which were proved to inhibit proliferative and exert pro-apoptotic effects on prostate tumor via activation of ER $\beta$ signaling [24]. Recently, more researches began to focus on the molecular basis for ethnic variation and found that several genetic alterations for prostate carcinogenesis were comparatively lower among Asian patients [25].

Selection bias might also contribute to the inconsistent results. Variations of PCa epidemiology among Asian populations could be attributed to differences in access to PSA screening, urology clinics, and available therapies [26]. PSA screening tests were not generally popularized in Asia; thus, prostate cancers in Asian patients were generally of higher stages and pathological scores before surgery. Besides, as quite a number of elder Asian patients were still concerned by surgical procedures, they would rather choose different types of androgen-deprivation therapy instead of RP as a first-line treatment towards regional prostate cancer [27]. The fluctuation of RP indications within different Asian regions might enhance heterogeneity among studies. Besides, the high heterogeneity could be further explained by different surgery methods (open or laparoscopic) and different confounders adjusted in the multivariate analyses.

The present study had some limitations. First, our study was a retrospective study in a tertiary referral hospital in China and thus may not represent the Chinese population as a whole. Second, since the patient number and follow-up time were limited, we were not able to clarify the impact of BMI on long-term prognosis. Third, the use of BMI was unable to distinguish fat from muscle. Other parameters like waist circumference, waist-to-hip ratio, and percentage of visceral adipose tissue [28] might be a better indicator for obesity.

Over the past few decades, the morbidity of obesity and PCa in Asian countries has shifted towards a more westernized high level [29]. On the contrary, Asian populationbased epidemiological studies discussing the relationship between obesity and PCa prognosis were still rare. Since populations across Asian countries shared similar racial background and living customs, which were quite different from Western populations, more prospective multicenter studies would be necessary to elaborate and confirm such a relationship in Asian populations. Furthermore, other risk factors [30] such as BMI in early, middle, and late adulthood, body weight changes before or after surgery, daily diet components, exercise levels, and unrevealed biological mechanisms in Asian populations should attract wider attention from urologists and scientists.

\section{Conclusions}

The present cohort study suggested that higher BMI was an independent risk factor for higher Gleason score, as 
Table 4 Overview and characteristics of studies discussing BMI and biochemical recurrence of prostate cancer in Asia

\begin{tabular}{|c|c|c|c|c|c|c|}
\hline Author, year [Ref] & Location & Patients & $\mathrm{BMI}\left(\mathrm{kg} / \mathrm{m}^{2}\right)$ & $\mathrm{HR}(95 \% \mathrm{Cl})$ & $\begin{array}{l}\text { HR per } 5 \mathrm{~kg} / \mathrm{m}^{2} \text { increase } \\
\text { of BMI }(95 \% \mathrm{Cl})\end{array}$ & $\begin{array}{l}\text { Adjusted } \\
\text { confounders }^{\mathrm{a}}\end{array}$ \\
\hline Bai 2015 & China & $\begin{array}{l}N=211,2006-2014 \\
F U T=24.5 \text { months }\end{array}$ & Continuous & $1.145(1.029-1.273)$ & $1.97(1.15-3.34)$ & $1,2,7,8$ \\
\hline Ohwaki 2015 [15] & Japan & $\begin{array}{l}N=283,2008-2012 \\
F U T=30 \text { months }\end{array}$ & $\geq 25$ vs. $<25$ & $0.83(0.40-1.72)$ & $0.83(0.40-1.72)$ & $1,2,7,8$ \\
\hline Koo 2014 [10] & Korea & $\begin{array}{l}N=880,2005-2011 \\
F U T=58.2 \text { months }\end{array}$ & $>23$ vs. $\leq 23$ & $0.63(0.46-0.89)$ & $0.63(0.46-0.89)$ & $2,5,6,7,8,14$ \\
\hline Hayashi 2014 [12] & Japan & $\begin{array}{l}N=703,2002-2009 \\
F U T=38.4 \text { months }\end{array}$ & Continuous & $1.07(1.01-1.14)$ & $1.40(1.05-1.93)$ & $1,2,7,8,9,10,15$ \\
\hline Narita 2013 [9] & Japan & $\begin{array}{l}N=1257,2001-2009 \\
F U T=49 \text { months }\end{array}$ & Continuous & $0.987(0.940-1.035)$ & $0.94(0.73-1.19)$ & $1,2,7,8,9,10,11$ \\
\hline Lee 2011 [13] & Korea & $\begin{array}{l}N=512,2003-2009 \\
F U T=37.8 \text { months }\end{array}$ & Continuous & $1.373(0.720-2.326)$ & $4.88(0.19-68.08)$ & $1,2,3,7,8,9,10$ \\
\hline Komaru 2010 [14] & Japan & $\begin{array}{l}N=173,1997-2007 \\
F U T=35 \text { months }\end{array}$ & $\geq 25$ vs. $<25$ & $1.398(0.694-2.817)$ & $1.40(0.69-2.82)$ & None \\
\hline Hisasue 2008 [8] & Japan & $\begin{array}{l}N=126,1998-2006 \\
F U T=17 \text { months }\end{array}$ & $\geq 26.4$ vs. $<26.4$ & $3.53(1.289-9.677)$ & $3.53(1.29-9.68)$ & $1,2,4,7,8,12,13$ \\
\hline
\end{tabular}

Ref reference, FUT follow-up time; other abbreviations as in Tables 1, 2, and 3

${ }^{a}$ Adjusted confounders: 1, age; 2, preoperative PSA; 3, prostate volume; 4, clinical stage; 5, lymphovascular invasion; 6, perineural invasion; 7, pathological Gleason score; 8 , positive surgical margin; 9 , extraprostatic extension; 10 , seminal vesicle invasion; 11 , lymph node involvement; 12 , surgical period; 13 , total testosterone; 14, pathological T stage; 15, adjuvant radiotherapy

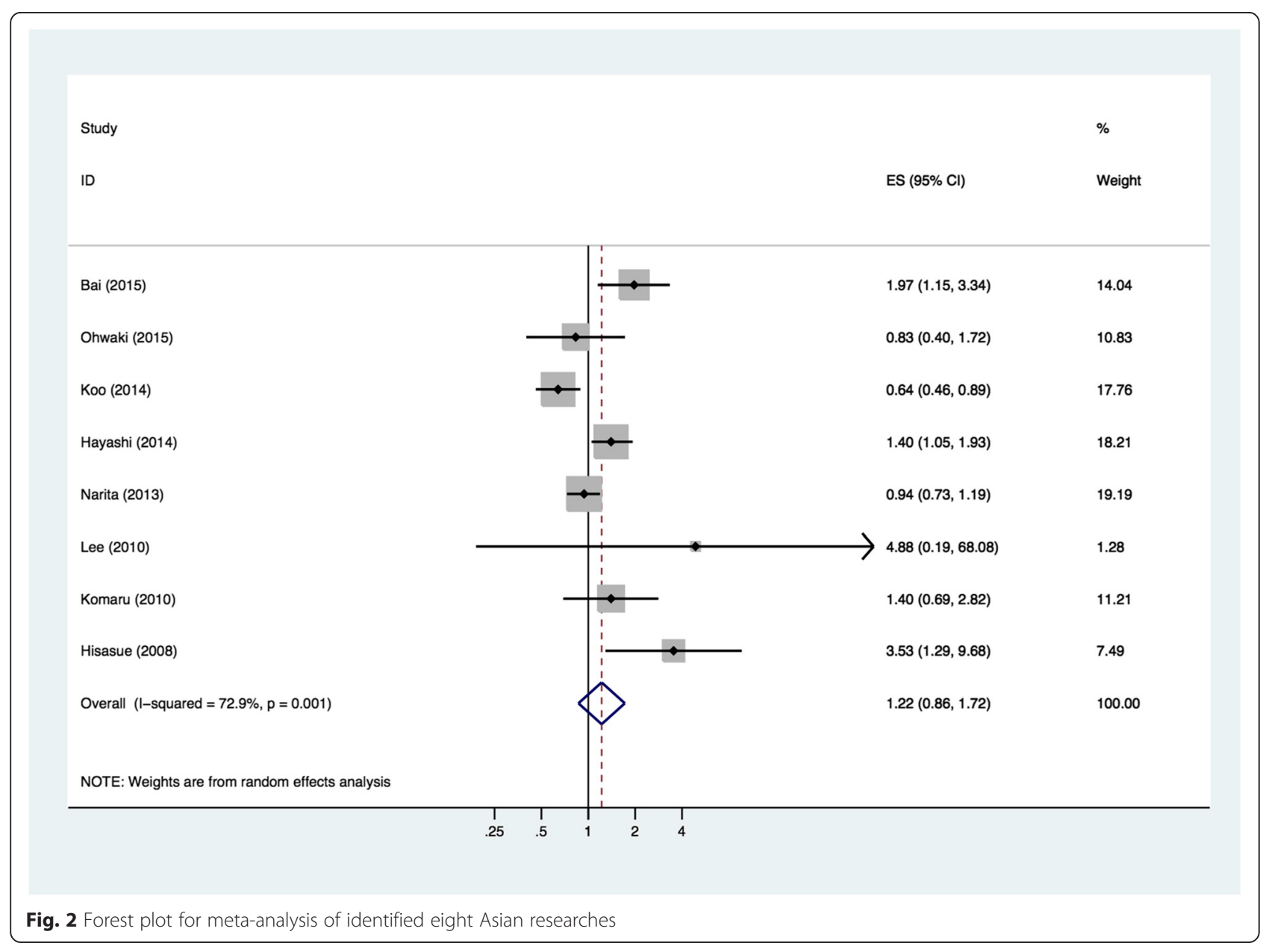


well as an independent predictor of BCR after RP in Chinese patients. Meanwhile, the meta-analysis of Asian studies detected a positive association without statistical significance between BMI and BCR. Thus, it might be beneficial for Chinese PCa patients with higher BMI to be treated more aggressively and followed more closely after RP.

\section{Abbreviations}

BCR: biochemical recurrence; BMl: body mass index; Cl: confidence interval; DRE: digital rectal examination; HR: hazard ratio; OR: odds ratios; PCa: prostate cancer; PSA: prostate-specific antigen; PV: prostate volume; RP: radical prostatectomy; TRUS: transrectal ultrasound.

\section{Competing interests}

The authors declare that they have no competing interests.

\section{Authors' contributions}

PDB, WHZ, JMH, and TY contributed to acquisition of clinicopathological data and follow-up of patients. PDB, MBH, HX, and $\mathrm{WHZ}$ participated in the design of the study and analysis of data. $\mathrm{MBH}$ drafted the manuscript. HWJ and QD conceived of the study, participated in coordination, and helped to modify the manuscript. All authors read and approved the final manuscript.

\section{Acknowledgements}

This study was sponsored by the National Natural Science Foundation of China (81272835), Outstanding Talents Cultivation Project of Shanghai Medical System (XBR2013092), Talents Development Foundation of Shanghai (201302), and Scientific Research Innovation Project of Shanghai Education Committee (14ZZ010). The funders had no role in study design, data collection and analysis, decision to publish, or preparation of the manuscript.

Received: 7 June 2015 Accepted: 28 October 2015 Published online: 05 November 2015

\section{References}

1. Wang YC, McPherson K, Marsh T, Gortmaker SL, Brown M. Health and economic burden of the projected obesity trends in the USA and the UK. Lancet. 2011;378:815-25.

2. McGrowder DA, Jackson LA, Crawford TV. Prostate cancer and metabolic syndrome: is there a link? Asian Pac J Cancer Prev. 2012;13:1-13.

3. Maclnnis RJ, English DR. Body size and composition and prostate cancer risk: systematic review and meta-regression analysis. Cancer Causes Control. 2006;17:989-1003.

4. Freedland SJ, Bañez LL, Sun LL, Fitzsimons NJ, Moul JW. Obese men have higher-grade and larger tumors: an analysis of the Duke Prostate Center database. Prostate Cancer Prostatic Dis. 2009;12:259-63.

5. Calle EE, Rodriguez C, Walker-Thurmond K, Thun MJ. Overweight, obesity, and mortality from cancer in a prospectively studied cohort of U.S. adults. N Engl J Med. 2003;348:1625-38.

6. Mallah KN, DiBlasio CJ, Rhee AC, Scardino PT, Kattan MW. Body mass index is weakly associated with, and not a helpful predictor of, disease progression in men with clinically localized prostate carcinoma treated with radical prostatectomy. Cancer. 2005;103:2030-4.

7. Discacciati A, Orsini N, Wolk A. Body mass index and incidence of localized and advanced prostate cancer-a dose-response meta-analysis of prospective studies. Ann Oncol. 2012;23:1665-71.

8. Hisasue SI, Yanase M, Shindo T, Iwaki H, Fukuta F, Nishida S, et al. Influence of body mass index and total testosterone level on biochemical recurrence following radical prostatectomy. Jpn J Clin Oncol. 2008;38:129-33.

9. Narita S, Mitsuzuka K, Yoneyama T, Tsuchiya N, Koie T, Kakoi N, et al. Impact of body mass index on clinicopathological outcome and biochemical recurrence after radical prostatectomy. Prostate Cancer Prostatic Dis. 2013;16:271-6.

10. Koo KC, Yoon YE, Rha KH, Chung BH, Yang SC, Hong SJ. Low body mass index is associated with adverse oncological outcomes following radical prostatectomy in Korean prostate cancer patients. Int Urol Nephrol. 2014;46:1935-40.
11. $H u M B, X u H$, Bai PD, Jiang HW, Ding Q. Obesity has multifaceted impact on biochemical recurrence of prostate cancer: a dose-response meta-analysis of 36,927 patients. Med Oncol. 2014;31:829.

12. Hayashi N, Matsushima M, Kido M, Naruoka T, Furuta A, Furuta N, et al. BM is associated with larger index tumors and worse outcome after radical prostatectomy. Prostate Cancer Prostatic Dis. 2014;17:233-7.

13. Lee SE, Lee WK, Jeong MS, Abdullajanov M, Kim DS, Park HZ, et al. Is body mass index associated with pathological outcomes after radical prostatectomy in Korean men? BJU Int. 2011;107:1250-5.

14. Komaru A, Kamiya N, Suzuki H, Endo T, Takano M, Yano M, et al. Implications of body mass index in Japanese patients with prostate cancer who had undergone radical prostatectomy. Jpn J Clin Oncol. 2010;40:353-9.

15. Ohwaki K, Endo F, Hattori K. Abdominal obesity, hypertension, antihypertensive medication use and biochemical recurrence of prostate cancer after radical prostatectomy. Eur J Cancer. 2015;51:604-9.

16. Jayachandran J, Bañez LL, Aronson WJ, Terris MK, Presti Jr JC, Amling CL, et al. Obesity as a predictor of adverse outcome across black and white race: results from the Shared Equal Access Regional Cancer Hospital (SEARCH) Database. Cancer. 2009;115:5263-71.

17. Freedland SJ, Isaacs WB, Mangold LA, Yiu SK, Grubb KA, Partin AW, et al. Stronger association between obesity and biochemical progression after radical prostatectomy among men treated in the last 10 years. Clin Cancer Res. 2005;11:2883-8.

18. Isom-Batz G, Bianco Jr FJ, Kattan MW, Mulhall JP, Lilja H, Eastham JA. Testosterone as a predictor of pathological stage in clinically localized prostate cancer. J Urol. 2005;173:1935-7.

19. Price RS, Cavazos DA, De Angel RE, Hursting SD, de Graffenried LA. Obesityrelated systemic factors promote an invasive phenotype in prostate cancer cells. Prostate Cancer Prostatic Dis. 2012;15:135-43.

20. Zhang Q, Sun LJ, Qi J, Yang ZG, Huang T. Influence of adipocytokines and periprostatic adiposity measurement parameters on prostate cancer aggressiveness. Asian Pac J Cancer Prev. 2014;15:1879-83.

21. Freedman JE, Larson MG, Tanriverdi K, O'Donnell CJ, Morin K, Hakanson AS. Relation of platelet and leukocyte inflammatory transcripts to body mass index in the Framingham heart study. Circulation. 2010;122:119-29.

22. Nandeesha H. Insulin: a novel agent in the pathogenesis of prostate cancer. Int Urol Nephrol. 2009:41:267-72.

23. Deurenberg P, Deurenberg-Yap M, Guricci S. Asians are different from Caucasians and from each other in their body mass index/body fat per cent relationship. Obes Rev. 2002;3:141-6.

24. Turner JV, Agatonovic-Kustrin S, Glass BD. Molecular aspects of phytoestrogen selective binding at estrogen receptors. J Pharm Sci. 2007;96:1879-85.

25. Zong Y, Goldstein AS, Huang J. The molecular basis for ethnic variation and histological subtype differences in prostate cancer. Sci China Life Sci. 2013;56:780-7.

26. Ito K. Prostate cancer in Asian men. Nat Rev Urol. 2014;11:197-212.

27. Akaza $\mathrm{H}$. Asian trends in primary androgen depletion therapy on prostate cancer. Cancer Biol Med. 2013;10:187-91.

28. Qu YY, Dai B, Kong YY, Chang K, Ye DW, Yao XD, et al. Influence of obesity on localized prostate cancer patients treated with radical prostatectomy. Asian J Androl. 2013;15:747-52.

29. Zhang L, Yang BX, Zhang HT, Wang JG, Wang HL, Zhao XJ. Prostate cancer: an emerging threat to the health of aging men in Asia. Asian $J$ Androl. 2011;13:574-8

30. Skolarus TA, Wolf AM, Erb NL, Brooks DD, Rivers BM, Underwood 3rd W, et al. American Cancer Society prostate cancer survivorship care guidelines. CA Cancer J Clin. 2014;64:225-49. 